\title{
Variation of black carbon and particulate matter in Bhubaneswar during the pre-monsoon: possible impact of meteorology and COVID-19 lockdown
}

\author{
Jyotishree Nath ${ }^{1,2}$, Subhasmita Panda ${ }^{1,2}$, Satya S. Patra ${ }^{1}$, Boopathy Ramasamy ${ }^{1}$ \\ and Trupti Das ${ }^{1, *}$ \\ ${ }^{1}$ Environment and Sustainability Department, and \\ ${ }^{2}$ Academy of Scientific and Innovative Research, CSIR-Institute of Minerals and Materials Technology, Bhubaneswar 751 013, India
}

\begin{abstract}
To combat the present COVID-19 pandemic, a countrywide lockdown (LD) was imposed in India from 25 March until 31 May 2020. This unique scenario brought a decline in various anthropogenic activities leading to a considerable decrease in the concentration of several atmospheric pollutants. In this scenario, CSIR-IMMT Bhubaneswar carried out black carbon (BC), $\mathbf{P M}_{10}$ and $\mathbf{P M}_{2.5}$ analysis through optical and gravimetric measurements, respectively, during March-May 2020 followed by a comparison with previous years (2017-2018) of observation. There was a reduction of $\sim 33 \%$ in average overall $\mathrm{BC}$ concentration along with a significant drop in PM10 (33\%) $(P<0.05)$ and PM $_{2.5}(\sim 38 \%) \quad(P<0.05)$ during the entire LD period as compared to 2017-2018. During LD, contribution from biomass burning was enhanced by almost 3 times as compared to 2017-2018. However, the simultaneous meteorological variation during the $L D$ period prevents clear distinction of the impact of lockdown on BC and PM.
\end{abstract}

Keywords: Black carbon, biomass burning, fossil fuel, lockdown, particulate matter.

\section{Introduction}

The World Health Organization (WHO) announced a global health emergency in the wake of the spread of the novel coronavirus (COVID-19). To curb the spread of this contagious disease, the Indian Government imposed a nationwide lockdown (LD) starting from 25 March till 31 May 2020 in different phases. Thus, the unprecedented restrictions provided researchers with an opportunity to access the influence of anthropogenic activities on the level of air pollutants. Different phases considered for the study are pre-lockdown: 1 March-23 March (LD-1): 24 March-14 April (LD-2): 15 April-3 May (LD-3): 4-17 May (LD-4) and 18 May-31 May.

\footnotetext{
*For correspondence. (e-mail: truptidas@immt.res.in)
}

In this context, the variation of black carbon (BC), $\mathrm{PM}_{10}$ and $\mathrm{PM}_{2.5}$ was studied over Bhubaneswar during March-May for 2017-2020. BC is usually emitted due to incomplete combustion of fossil fuel, biomass burning, and biogenic sources through multi-phase reactions ${ }^{1}$. BC has a usual lifetime of seven to ten days in the absence of rainfall and hence can be transported easily from long distance $^{2,3}$. Furthermore, BC, as a light-absorbing aero$\mathrm{sol}^{4}$, impairs visibility ${ }^{5}$ and impacts the radiation budget of the earth ${ }^{6,7}$. On the other hand, particulate matter (PM), especially $\mathrm{PM}_{2.5}$ (aerodynamic diameter $<2.5 \mu \mathrm{m}$ ) is an important indicator of anthropogenic contribution to the overall PM mass, as it is generated through both primary and secondary processes ${ }^{8}$ whereas $\mathrm{PM}_{10}$ (aerodynamic diameter $\leq 10 \mu \mathrm{m}$ ) being the coarser fraction, is generated through various mechanical processes over land and the ocean ${ }^{9} . \mathrm{PM}_{10}$ forms a predominant part of particulate matter giving rise to a number of respiratory diseases because a major portion of it gets trapped in the nasal passage and upper respiratory tract ${ }^{10}$. With respect to its small size, larger surface area and long residence time in the atmosphere, $\mathrm{PM}_{2.5}$ can act as a carrier of toxic substances that finds a way deep within the human respiratory system, thus triggering several pulmonary and cardiovascular diseases ${ }^{11}$. $\mathrm{PM}_{2.5}$ can also influence the weather pattern and climate by acting as cloud condensation nuclei $(\mathrm{CCN})$, and thus, changing the microphysical properties of clouds and the hydrological cycle as well ${ }^{12}$.

Previous studies over this region have brought out pertinent information regarding the impact of meteorology and long-range transport on the spatial and temporal variation of important pollutants like particulate matter $\left(\mathrm{PM}_{10}\right.$ and $\mathrm{PM}_{2.5}$ ) and $\mathrm{BC}^{13}$. A recent study also discussed the impact of LD on several atmospheric trace gases $\mathrm{O}_{3}, \mathrm{CO}$, $\mathrm{NO}_{x}$ along with $\mathrm{BC}$ over Bhubaneswar ${ }^{14}$. The countrywide LD during the current pandemic brought a huge curtailment of the anthropogenic activities especially vehicular movement. Hence this motivated us to make 


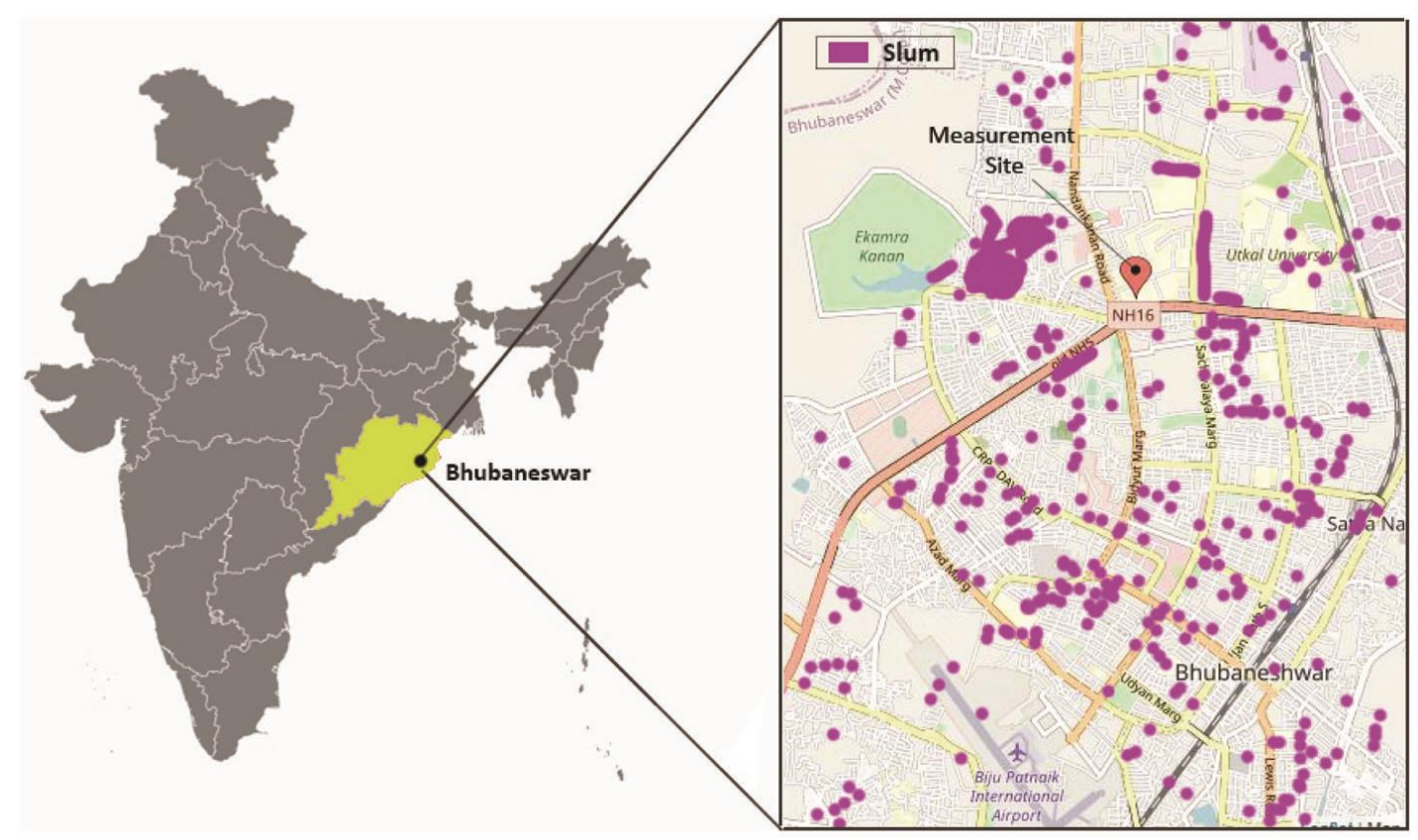

Figure 1. Odisha state and Bhubaneswar city in India map. Arial view of Bhubaneswar city depicting the various slum areas located within the city ${ }^{39}$.

use of this unique scenario to study the spatial/temporal variation and source contribution of two major pollutants like BC and PM, which could provide some imperative scientific information for the region. Thus, the study aims to evaluate the impact of $\mathrm{LD}$ on particulate pollutants like, $\mathrm{BC}, \mathrm{PM}_{10}$ and $\mathrm{PM}_{2.5}$ concentrations over Bhubaneswar. This would be considered as a baseline data for the region and compared with the previous year's observations to understand the impact of local/regional emission sources as well as meteorology on the pollution load.

\section{Site description, methodology and general meteorology}

\section{Site description}

The study was carried out at CSIR-Institute of Minerals and Material (IMMT), Bhubaneswar $\left(20.27^{\circ} \mathrm{N}, 85.84^{\circ} \mathrm{E}\right)$. Being the capital of Odisha state, Bhubaneswar, an upcoming smart city, is now considered as one of the non-attaining cities as per the National Green Tribunal of India. The sampling site is located inside a green campus in the heart of the city with national, state highways and slums in its close proximity. Furthermore, there are a number of thermal power plants ${ }^{15}$, several small and largescale cement, fertilizer, beverage, biomedical waste management, agro, steel, paper, textile and food processing industries along with two main shipping harbours at close proximity of Bhubaneswar. A more detailed description of this site is given elsewhere ${ }^{15,16}$ (Figure 1).

\section{Methodology}

BC data was obtained from Aethalometer (Magee Scientific, Model: AE33), which was operational at CSIR-IMMT campus during the lockdown period. This instrument, sample line equipped with a 2.5 -micron size cyclone and a rain/insect guard, was operated continuously at a flow rate of 2 LPM and measured optical attenuation at seven-channel wavelengths of $370,470,520,590$, 660,880 and $950 \mathrm{~nm}$ respectively. The total $\mathrm{BC}$ mass concentration was estimated from the $880 \mathrm{~nm}$ wavelength. Furthermore, Aethalometer model or Sandradewi model ${ }^{17,18}$ was used to estimate contribution from fossil fuel and biomass using 470 and $950 \mathrm{~nm}$ wavelengths. Sandradewi model ${ }^{18}$ was based on aerosol spectral absorption principle which assumes particles generated from traffic and other fossil fuel combustion absorbs in the long visible and near infrared (IR) wavelength ( 600$950 \mathrm{~nm}$ ) whereas particles generated from biomass burning absorb near UV and lower visible wavelength $(\sim 300-500 \mathrm{~nm})^{1,17,18}$. However, a major drawback of the model is that it disrespects the impact of mineral dust and coal combustion contribution in the UV range ${ }^{19}$. Thus, the biomass burning (BB) percentage contribution to total $\mathrm{BC}$ was taken from the instrument directly by following the procedure given in AE33 manual (Magee Scientific, 2016).

The mass concentrations of biomass burning $\left(\mathrm{BC}_{\mathrm{bb}}\right)$ and fossil fuel $\left(\mathrm{BC}_{\mathrm{ff}}\right)$ were calculated as

$$
\mathrm{BC}_{\mathrm{bb}}=\mathrm{BB} \times \mathrm{BC},
$$




$$
\mathrm{BC}_{\mathrm{ff}}=(1-\mathrm{BB}) \times \mathrm{BC} \text {. }
$$

Moreover, the fossil fuel percentage (FF) contribution to total $\mathrm{BC}$ was derived using the equation

$$
\mathrm{FF}=\left(\frac{\mathrm{BC}(\mathrm{ff})}{\mathrm{BC}}\right) \times 100
$$

The 24-hour $\mathrm{PM}_{10}$ and $\mathrm{PM}_{2.5}$ sampling was carried out at the roof-top of CSIR-IMMT using a high volume sampler (Envirotech, APM $460 \mathrm{NL}$ ) and a low volume sampler (Envirotech, $550 \mathrm{MFC}$ ) at a flow rate of $1 \mathrm{~m} \mathrm{~s}^{-1}$ and 16.7 LPM respectively. The samples were collected twice a week using a pre-baked Whatman, quartz microfiber filter paper for both $\mathrm{PM}_{10}$ and $\mathrm{PM}_{2.5}$ and the initial final weight of the filter paper was measured by Sartorius weighing balance with $0.00001 \mathrm{mg}$ sensitivity. A more detailed description of the standard procedure has been given elsewhere ${ }^{20}$. PM measurements were also made using a portable aerosol spectrometer PAS1.108 (GRIMM Aerosol Technik GmbH \& Co. KG, Dorfstrasse-9, Germany) during March-May 2020 on specific days. PAS 1.108 is a sophisticated optical particle counter with 15 size channels (range: $0.3-20 \mu \mathrm{m}$ ) for the estimation of particle mass concentrations in three size fractions $\left(\mathrm{PM}_{1}\right.$, $\mathrm{PM}_{2.5}$ and $\mathrm{PM}_{10}$ ) in this study. It counts particle numbers and is based on the light scattering principle converted to particle mass concentration at a sampling flow rate of 1.2 LPM. It has a laser $(40 \mathrm{~mW} \max$ power $)$ that scans to detect small particles at $0.5 \mathrm{~mW}$ and detect larger particles $30 \mathrm{~mW}$ alternatively ${ }^{21}$. Studies in the past have reported the performance of PAS-1.108 for different environments ${ }^{22,23}$. As gravimetric measurements of $\mathrm{PM}_{10}$ could not be done during the LD phases in 2020, for scientific interpretation, the data from PAS 1.108 were used.

\section{Statistical analysis}

To support the observed results, paired $t$-tests were conducted at $95 \%$ confidence, with a null hypothesis as no difference in historical and current observations and alternative hypothesis as a difference exists. The critical $p$-value for the $t$-test is 0.05 , i.e. anything more significant than that indicates acceptance of the null hypothesis, and less than 0.05 indicates acceptance of the alternative hypothesis.

\section{General meteorology}

Meteorology always plays a crucial role in determining the pollution level and its dilution ${ }^{24}$. Therefore, the time series data for temperature, rainfall and humidity for the years 2017, 2018 and 2020 are depicted in Figure 2 whereas the wind speed and wind direction are shown in Figure 3. The meteorological parameters were derived from the archives of weather underground (https://www. wunderground.com/ $/)^{25}$ for March-May for the respective years as described above. March-May is typically characterized as the pre-monsoon period, and during this season, the profound influence of marine air mass from the Bay of Bengal (BoB) is observed ${ }^{15,16}$. The site, in general, experiences high temperatures varying from $27^{\circ} \mathrm{C}$ to $32^{\circ} \mathrm{C}$ and low humidity 55-85\% during March-May ${ }^{20}$. However, along with LD, frequent rain episodes observed during 2020 due to depression over BoB could have played an important role in scavenging pollutants, which will be discussed in later sections.

\section{Back trajectory analysis}

The five-day backward air masses arriving at Bhubaneswar were recorded using NOAA Air Resource Laboratory (ARL) Hybrid Single-Particle Model at $100 \mathrm{~m} \mathrm{agl} \mathrm{for}$ PLD and LD-3 (refs 14, 26, 27) (Supplementary Figure 1). Moderate Resolution Imaging Spectro-radiometer (MODIS), aboard Aqua and Terra satellites (C6 version), derived from NASA FIRMS, were used to understand the impact of biomass burning over the study site ${ }^{14,28,29}$. Fires with $80 \%$ and above detection confidence alone were considered to remove false fires.

\section{Results and discussion}

\section{Diurnal variation of $B C$ during the pre-lockdown and lockdown phases}

To evaluate the influence of $\mathrm{LD}$ on $\mathrm{BC}$ concentrations, observations during 2020 were compared relative to

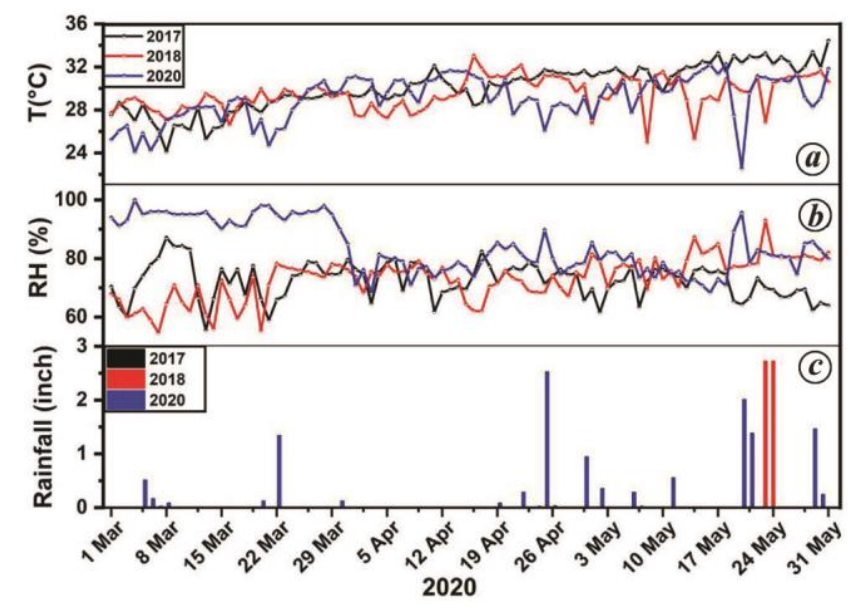

Figure 2. Temporal variation of meteorological parameters (rainfall, humidity and temperature) for the three different years $(2017,2018$ and 2020) of observation in Bhubaneswar. 
previous year's (2017-18) BC mass concentration. The Aethalometer (AE-33) was not operational during March-May 2019 due to some unavoidable circumstances (construction/maintenance at the observation site and major power failure followed by cyclone Fani), owing to which the year 2019 data could not be included in this study.

The average diurnal pattern of the BC mass concentration for PLD and various phases of LD (LD-1, LD-2, LD3 , LD-4) have been compared to the mean $\mathrm{BC}$ data of the similar period during the year 2017-18 (Figure 4). It was indeed interesting to note that during the PLD phase (1-23 March), the diurnal pattern for 2017-18 and for 2020 depicted a clear morning peak between 6:00 and 7:00 $\mathrm{h}$ followed by a decrease in concentration during the afternoon hours (until 16:00 h) which then increased gradually during the evening (until 21:00 h). This is a typical diurnal pattern observed in most of the urban areas and is a representation of the interaction of lower atmosphere meteorology and anthropogenic emissions from local and the regional sources ${ }^{30,31}$. The morning peak is generally due to the evolution of the boundary layer and fumigation effect along with the anthropogenic activities, whereas the decrease in concentration during the afternoon is because of the dilution of the pollutants due to convection. The evening rise is again linked with the build-up of the $\mathrm{BC}$ mass due to the emission from the evening traffic and other anthropogenic activities like cooking, industrial and thermal power plant emissions, etc., which is a typical representation of urban areas and has been reported earlier from this $\operatorname{site}^{30}$. However, although it was a normal phase and it is expected that the mean BC concentration would be more or less similar or even a little higher during the year 2020 compared to the same time period of 2017-18, provided the meteorology as well as the emission sources remain constant. Although a typical bimodal pattern was observed, a more than $50 \%$ reduction in the $\mathrm{BC}$ mass concentration was observed during the year 2020 (Figure $4 a$ ).

During LD-1, a distinct bi-modal pattern was observed with a distinct morning peak during 2017-18, however during 2020 this typical bi-modal peak was not distinct (Figure $4 b$ ). Although the BC mass concentration peaked at around 7:00 $\mathrm{h}$, there was a subsequent decrease in the BC mass concentration during the evening hours. Furthermore, an overall decrease in BC mass in PLD phase in comparison to $2017-18$ of the same period was observed. During the first phase, the observed BC mass concentration was still in the range of $1-1.5 \mu \mathrm{g} / \mathrm{m}^{3}$ due to emissions from thermal power plants, fire events, essential goods carrier and the use of biomass for cooking purposes in the various slum areas (Figure 1) and villages surrounding Bhubaneswar. Apart from that, a longer lifetime of $\mathrm{BC}$ in the lower atmosphere results in accumulation and hence contributes to the overall $\mathrm{BC}$ mass during lockdown ${ }^{32}$. BC mass concentration was observed to be minimum $\left(0.45 \mu \mathrm{g} / \mathrm{m}^{3}\right)$ during LD-2 (15 April-3 May) in comparison to the previous year of observation and PLD and LD-1 (Figure $4 c$ ). This is indeed interesting to note that vehicular emissions are a major contributor to $\mathrm{BC}$ mass concentration over the site; therefore, with a reduction in the vehicular movement for five consecutive weeks, there was a distinct fall in the $\mathrm{BC}$ mass concentration during LD-2. However, we could see a faint bimodal peak during this period possibly due to the various local biomass burning activities as well as from emissions pertaining to essential activities. During LD-3 (4-17 May), when partial vehicular movement permit was given and people started commuting, bi-modal peak during morning and evening hours became somewhat distinct, although the overall $\mathrm{BC}$ mass concentration was still lower than PLD and the LD-1 phase during 2020 but there was a partial increase in BC mass concentration in comparison to 2017-18 (Figure $4 d$ ). This has been discussed in detail in the next section. During LD-4 (18-31 May), there was an increase in the overall $\mathrm{BC}$ mass concentration while the bi-modal peaks during the morning and evening hours were quite flattened in comparison to 2017-18. Overall, the BC mass concentration was lowest during LD-2 than LD-3 and LD-4 period which distinctly supports vehicular emissions to be a major contributor to the overall $\mathrm{BC}$ mass concentration over this site. This was further validated by observing a distinct rise in evening peak of BC concentration during LD-3 and LD-4 (Figure $4 e$ ). Pertaining to the restrictions in vehicular movement during the LD period, it is presumed that the observed evening BC mass was mostly due to the accumulation caused by the shrinking boundary layer as well as due to emissions from biomass burning activities in nearby areas.

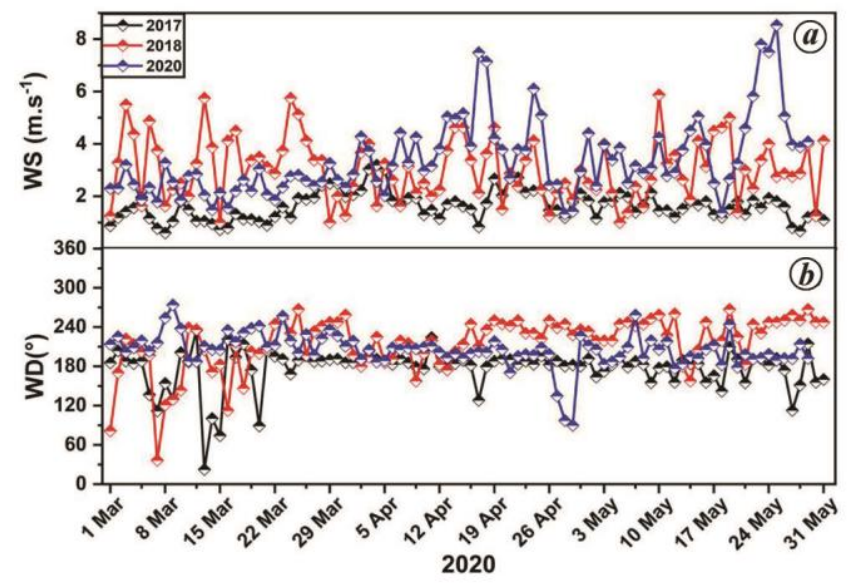

Figure 3. Temporal variation of meteorological parameters (wind speed and wind direction) for the three different years $(2017,2018$ and 2020) of observation in Bhubaneswar. 

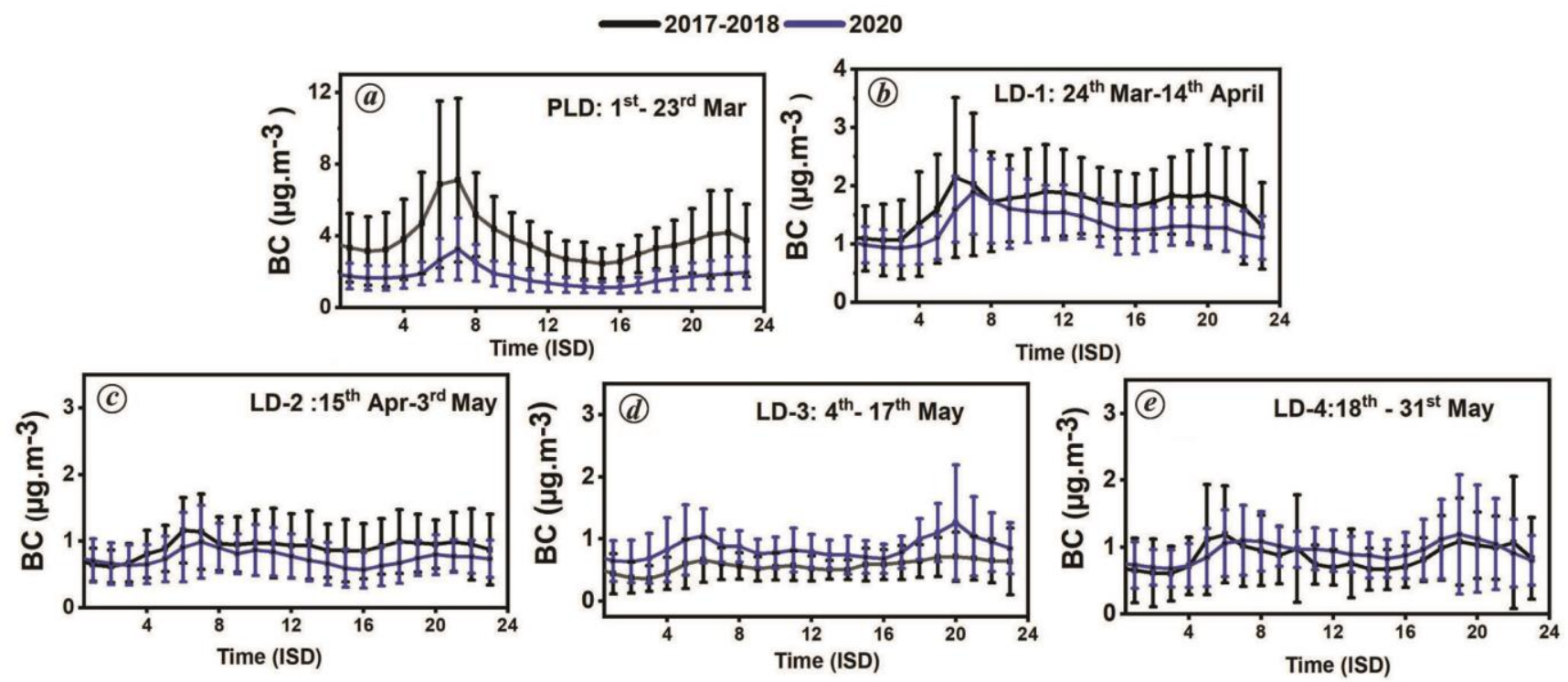

Figure 4. Mean diurnal pattern of BC mass during (a) PLD (1-23 March), (b) LD-1 (24 March-14 April), (c) LD-2 (15 April-3 May), (d) LD-3 (4-17 May), (e) LD-4 (18-31 May) for 2017-18 and 2020.

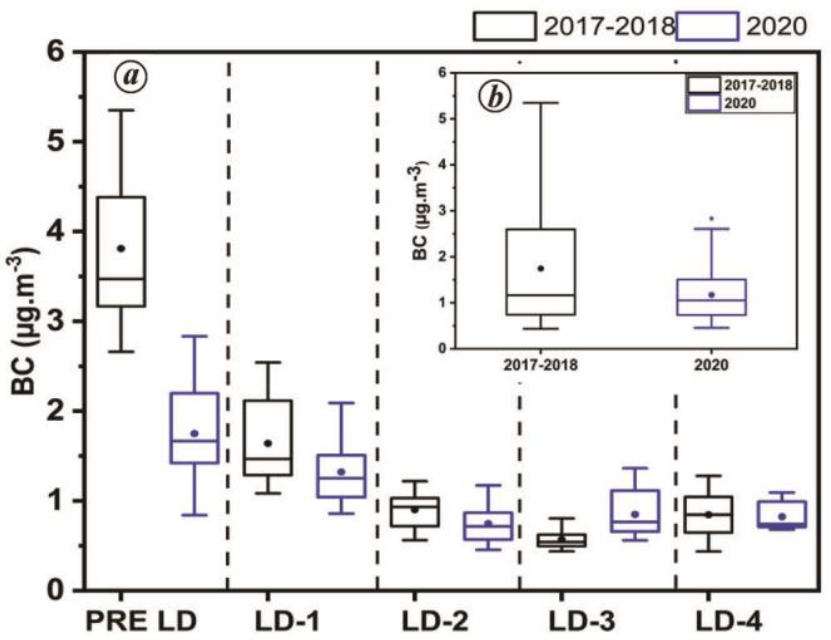

Figure 5. a, Temporal variation of $\mathrm{BC}$ for various phases of lockdown in 2020 and the mean BC mass for the same period during 2017 18 represented in box-whisker plots, the box represents $25-75 \%$ of the distribution of $\mathrm{BC}$ while the horizontal line and the circle represent the median and mean of the distribution. $\boldsymbol{b}$, Box whisker plots for the overall BC mass concentration for the study period March-May month (2017-18 and 2020).

\section{Temporal variation and source apportionment of $B C$}

The temporal variation in $\mathrm{BC}$ mass concentration has been represented through box whisker plots, where the box represents the dispersion of the $\mathrm{BC}$ mass within 25 and 75 percentiles whereas the middle line represents the median and the dot within the box represents the mean $\mathrm{BC}$ mass concentration. The minimum and maximum $\mathrm{BC}$ mass concentration is represented by the whiskers. It was observed that $\mathrm{BC}$ mass variation follows the same trend for all the years $(2017-18,2020)$ with maximum concen- trations during March and minimum levels during May (Figure $5 a$ ). This is attributed to a significant increase in temperature $(p \perp 0.05)$ and decrease in humidity $(p \perp 0.05)$ from March to April (Figure 2) which leads to dilution of BC level. Furthermore, during April and May, the profound influence of marine mass (Figure 3) over the observation site might have helped to reduce the $\mathrm{BC}$ concentrations subsequently ${ }^{14,16}$. Overall, during LD (2020) $\sim 33 \%(p \perp 0.05)$ in BC concentration was reduced as compared to the same time frame of the previous year. (Supplementary Figure 2) shows the general statistics of BC mass concentration observed during 2017, 2018 and 2020 whereas Supplementary Table 1 depicts the BC mass concentration during the PLD and the four LD phases in 2020 along with the BC mass fraction observed for the same time frame for the years 2017 and 2018. It was indeed interesting to observe that the average $\mathrm{BC}$ mass concentration was $1.74 \pm 0.67 \mu \mathrm{g} / \mathrm{m}^{3}$ during the PLD in the year 2020 whereas for the same time frame of 2017 and 2018 the BC mass was $4.78 \pm 2.3$ and $2.83 \pm$ $1.65 \mu \mathrm{g} / \mathrm{m}^{3}$ respectively. It was essential to study why the BC concentration during the PLD phase in the year 2020 was $54.12 \%$ and $38.5 \%$ lower than the BC mass for the same period in 2017 and 2018 respectively. The observations depicted that during 1-23 March 2020, there were several rain events with maximum of 1.5 inch of rain recorded on 22 of March when a Janata curfew was also imposed across the country for the entire day (Figure 2) all of which could have contributed to the lower BC mass concentration in comparison to 2017 and 2018 when there was comparatively less rainfall. It can also be observed (Supplementary Figure 1) that wind from the south and south-eastern sector was predominant in 2020, resulting in the transport of comparatively cleaner air mass. 
Although a few air parcel travelled through the polluted north-western part, however, the fire counts in 2020 were seen to be the minimum. This also could have impacted the BC mass concentration in PLD phase of 2020. The highest $\mathrm{BC}$ concentration in 2017 during the same period was attributed to the minimum wind speed (Figure 3) which could have facilitated an accumulation effect of the regional/local emissions. Further, there was a shift in the use of solid biofuels such as wood, coal, etc. to liquefied petroleum gas (LPG) for cooking purposes under the Ujjwala scheme in Odisha (https://timesofindia. indiatimes.com/city/bhubaneswar/34-lakh-beneficiariesof-ujjwala-scheme-in-odisha/articleshow/66101253.cms). As shown in Figure 1, the study site is surrounded by slum areas which could have used biofuels for cooking purposes in 2017, thus contributing to a higher BC mass. Moreover, the increased use of LPG, a cleaner fuel, also proved to be a remarkable step in climate, social and human benefits as well. The decrease in BB concentration from 2017 to 2018 (Supplementary Figure 3a) is another evidence from the fact that most of the incoming air masses came from marine source.

Thereafter, LD was imposed, pertaining to which there was a reduction in average $\mathrm{BC}$ mass concentration (mean: $1.32 \pm 0.36 \mu \mathrm{g} / \mathrm{m}^{3}$ ) during LD-1 (Figure $5 a$ ). Although the contribution from thermal power plants and biomass burning was still existent as a part of the essential services during the $\mathrm{LD}$ phases, the complete shutdown during LD-1 and LD-2 brought about a reduction of $19.38 \%$ and $17.17 \%$ respectively, in average $\mathrm{BC}$ concentration compared to the same period of 2017-18 (Figure $5 a$ ). The plummet in first and second phases of LD might be due to curtailment of vehicular pollution which is a major contributor of $\mathrm{BC}$ mass over the region ${ }^{14,31}$.

There was a partial relaxation in LD beyond 3 May 2020 , when government offices and other private sector establishments became operational and vehicular movement was also initiated. Interestingly, it was observed that during LD-3, there was a $49.11 \%$ increase in the overall BC mass during 2020 in comparison to the mean of 2017-18. This rise in BC concentration was again a matter of speculation that needs further investigation. Therefore, we took help of the backward trajectory analysis for the same period (Supplementary Figures 1 and 3). Interestingly, we observed that during 2020, polluted wind mass travelled through the continental areas from the northern sectors crossed the marine region before reaching the observation site, thus contributing to a slight increase in the overall $\mathrm{BC}$ mass over the observation site. As BC is generally a mixture of nano sphere soot and additional material and the former has least solubility, it is believed that $\mathrm{BC}$ originating from the continental areas is retained even if the wind mass travels over the marine region for a while ${ }^{33,34}$. However, during 2017 and 2018 majority of air mass travelled through the Bay of Bengal carrying partially clean air mass. Although parts of the
Bay of Bengal and the Indian Ocean also receive pollutants from the adjacent coastal areas ${ }^{35}$, the continental air mass was quite evident to carry more pollutant load in this case which could have contributed to the overall BC mass during the third lockdown phase in 2020.

Further, during the fourth phase of LD with more relaxation, the anthropogenic pollution load also increased subsequently. It was observed that there was $8.66 \%$ increase in mean BC load during 2020 in comparison to the same period during 2017-18. Also, the local meteorology had its role in influencing the pollutant concentration over the region. There were several rain events during the last week of May 2020 as well as in 2017-18. Further, the study site also experienced a very high wind speed due to the severe cyclonic storm Amphan that passed the Odisha coast during 19-20 May 2020. However, a detailed analysis of the same is beyond the scope of this study.

Apart from that, during the entire period of observation, the median values for the respective months during the year 2020 were nearly comparable (Supplementary Table 1), which indicates that there was no major episodic contribution to $\mathrm{BC}$ mass concentration over the region. As discussed earlier, the lifetime of $\mathrm{BC}$ in the lower atmosphere ranges from days to weeks to months ${ }^{31}$. This could have influenced the $\mathrm{BC}$ concentration during $\mathrm{LD}$ phases along with the biomass burning activities in nearby slum areas as well as the villages surrounding the Bhubaneswar city. However, during March 2017 and 2018 the median values were comparatively higher, which supports the influence of anthropogenic emissions from myriad sources. Further, the box whisker plot representing the overall BC mass for the different years of observation (Figure $5 b$ ) depicted that although the median was comparable for 2017-18 and 2020, the former was positively skewed and the latter was more or less symmetric. This also explains a myriad emission sources contributing to the BC mass during 2017-18, while in 2020 the sources were more consistent.

It was also observed that fossil fuel (FF) emissions were the major contributors to the average $\mathrm{BC}$ mass concentration during 2017-2018 (90\%) whereas the rest $(10 \%)$ came from biomass burning (BB) (Figure 6). These observations were similar to previous reports over the region ${ }^{20}$. However, during 2020, with the complete curtailment of inter- and intra-city transportation during April (LD-1 and 2) and partial restrictions in May (LD-3 and 4), there was a drastic change in the emission sources. It was observed that during the PLD phase (1 st2nd week of March 2020), FF emissions majorly (84\%) contributed to the overall $\mathrm{BC}$ mass concentration, however as the LD phases began during the 3rd week of March 2020, there was a shift from FF to BB emissions contributing significantly towards the $\mathrm{BC}$ mass concentration (Figure 6). During LD-1, BB contribution increased by $\sim 2$ times, whereas during LD phases 2 and 3, it showed 
an overall increment of $\sim 5$ times compared to the previous year of the same time frame. During the entire LD phase, FF and $\mathrm{BB}$ contribution was $70 \%$ and $30 \%$ respectively to the overall BC mass. Sources for the FF fractions during $\mathrm{LD}$ phases were due to emission from several thermal power plants around Bhubaneswar $(\sim 60 \mathrm{~km})$, which were operational as a part of the essential services. Also, there was movement of goods vehicles on the nearby National Highway (NH-16 and NH-203). Apart from these, the site being adjacent to a major corporate hospital was influenced by emissions from the movement of ambulance and other vehicles as a part of the regular essential service, which altogether could have generated $\mathrm{BC}$ mass through $\mathrm{FF}$ emissions. In the absence/reduction in vehicular traffic, BB emerged as significant emission sources in this area.

In 2020, it was observed that mostly the local sources were the major contributors to the overall $\mathrm{BC}$ mass. There are several slum areas within the Bhubaneswar city (Figure 1), where the locals use biomass/wood for cooking purposes. Further, during the LD phase, many NonGovernmental Organizations participated in mass cooking events in order to feed the needy and homeless people of the city and the nearby areas as well (Supplementary Figure 3a). Therefore, despite LD, local burning effects were still active over the region, which contributes to the total mass of BC. These observations supported the fact that a restriction in only the vehicular movement, even for a couple of weeks, resulted in 33\% decline in BC mass concentration.

\section{Variability of $P M_{10}$ and $P M_{2.5}$ for four consecutive years}

Figures 7 and 8 show 24-hour average $\mathrm{PM}_{10}$ and $\mathrm{PM}_{2.5}$ mass concentration for the years 2017-2018 and 2020

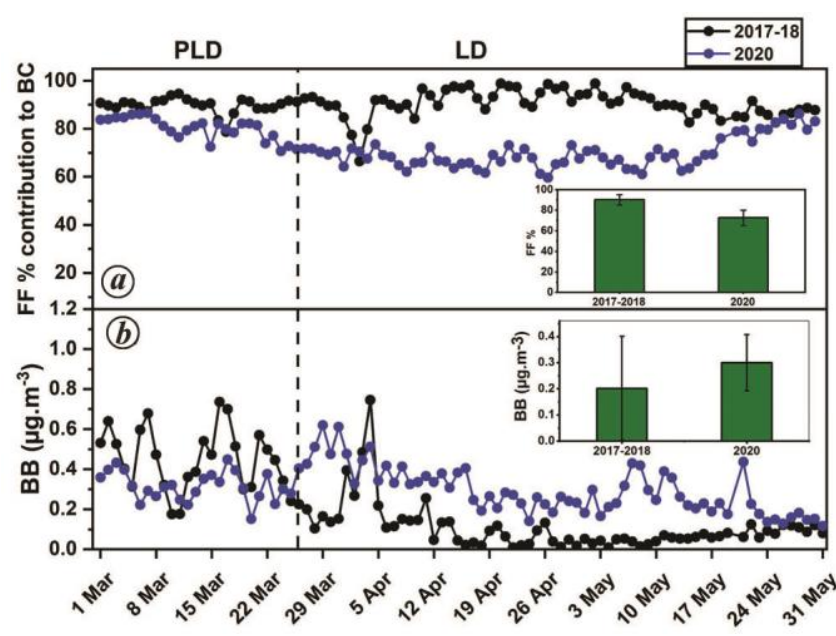

Figure 6. Percentage contribution of fossil fuel (FF) and biomass burning (BB) emissions to BC mass during the different years of observation $(2017-18,2020)$. over Bhubaneswar. As described earlier, the box represents $25-75 \%$ of the distribution of the particulate matter, for the month of March-May. The horizontal line and the circle represent the median and mean of the distribution. The mean concentration of $\mathrm{PM}_{10}$ and $\mathrm{PM}_{2.5}$ was found to be $47.18 \pm 20.8 \mu \mathrm{g} \mathrm{m}^{-3}$ (median, $45.55 \mu \mathrm{g} \mathrm{m}^{-3}$ ) and $42.3 \pm 17.1 \mu \mathrm{g} \mathrm{m}^{-3}$ (median, $42.04 \mu \mathrm{g} \mathrm{m}^{-3}$ ) respectively, during 2017-2019. While during 2020, when LD was imposed, both $\mathrm{PM}_{10}$ and $\mathrm{PM}_{2.5}$ were reduced to $31.68 \pm 19.16 \mu \mathrm{g} \mathrm{m}^{-3}$ (median, $25.09 \mu \mathrm{g} \mathrm{m}^{-3}$ ) and $27.26 \pm 23.17 \mu \mathrm{g} \mathrm{m}^{-3}$ (median, $23.17 \mu \mathrm{g} \mathrm{m}^{-3}$ ) respectively. Thus, a significant decline of $33 \%(p \perp 0.05)$ in $\mathrm{PM}_{10}$

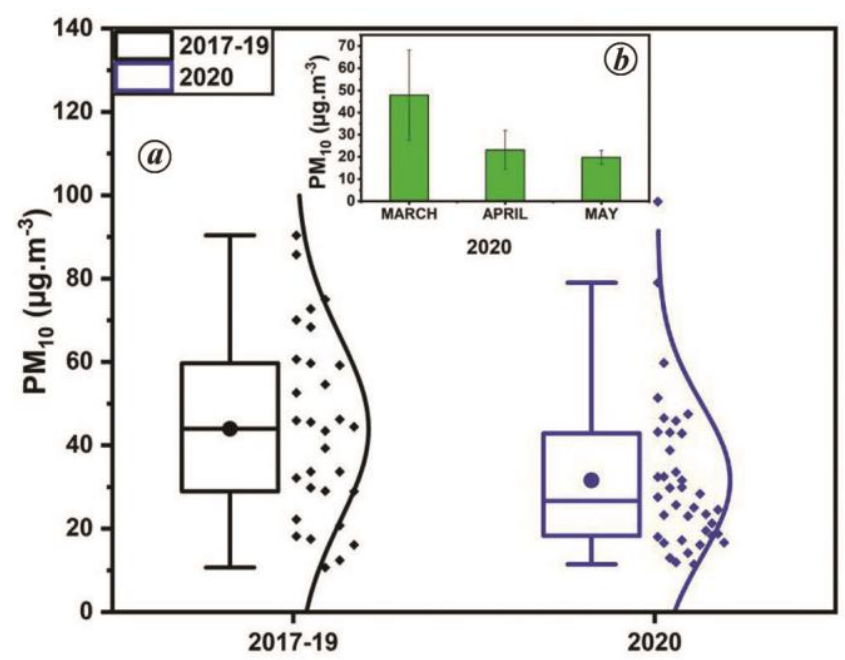

Figure 7. $\boldsymbol{a}$, Monthly average $\mathrm{PM}_{10}$ mass concentration over Bhubaneswar. The box represents $25-75 \%$ of the distribution of $\mathrm{PM}_{2.5}$, for 2017-2019 and 2020 while the horizontal line and the circle represent the median and mean of the distribution. $\boldsymbol{b}$, Monthly variation of $\mathrm{PM}_{10}$ during lockdown.

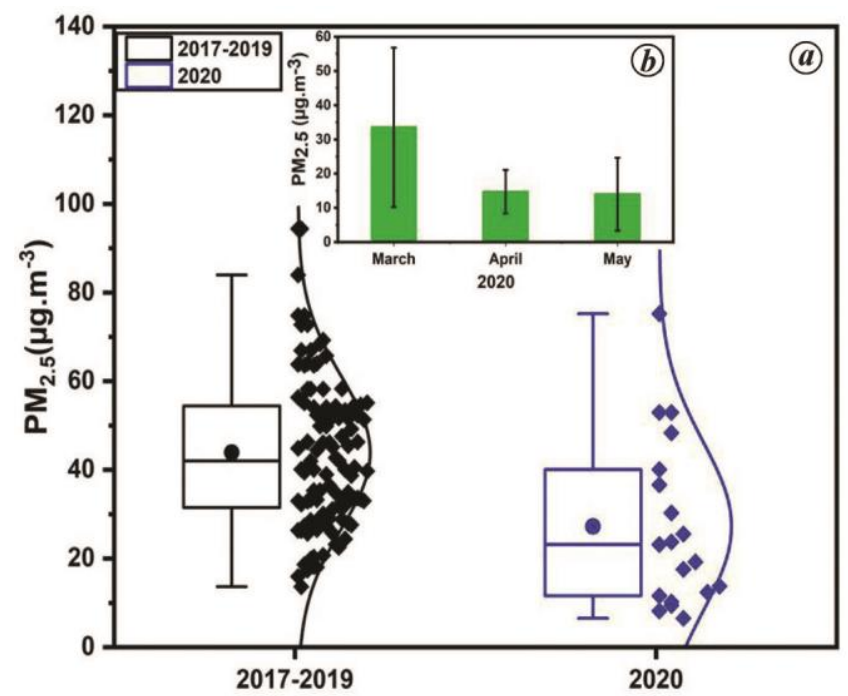

Figure 8. $\boldsymbol{a}$, Monthly average $\mathrm{PM}_{2.5}$ mass concentration over Bhubaneswar. The box represents $25-75 \%$ of the distribution of $\mathrm{PM}_{2.5}$, for 2017-2019 and 2020 whereas the horizontal line and the circle represent the median and mean of the distribution. $\boldsymbol{b}$, Monthly variation of $\mathrm{PM}_{2.5}$ during lockdown. 
and 38\% $(p \perp 0.05)$ in $\mathrm{PM}_{2.5}$ was observed during $\mathrm{LD}$ compared to 2017-2019. Further it was also observed that for the years 2017-2019, $\mathrm{PM}_{10}$ (Figure 7) and $\mathrm{PM}_{2.5}$ (Figure 8) data were symmetric whereas for the year 2020 , both coarse and fine particulate concentrations were positively skewed. A slightly higher reduction in $\mathrm{PM}_{2.5}$ mass fraction during the lockdown phases, in comparison to the $\mathrm{PM}_{10}$ mass fraction, is indicative of the curtailment in anthropogenic, especially vehicular emissions. Also, a similar plummet in $\mathrm{PM}_{2.5}$ level was reported in other stations over the eastern parts of the country, viz. Gorakhpur, Patna, Gaya, Brijrajnagar and Kolkata during lockdown over 2019 (ref. 36). Moreover, $\mathrm{PM}_{2.5}$ shows a diminution of 1.7 times during 2020 over the last three years (2017-2019). Likewise, Delhi shows a historic reduction of $\sim 45 \%$ in $\mathrm{PM}_{2.5}$ during lockdown (MarchApril) compared to same time period during 2019 (ref. 37). Similarly, a prominent fall in $\mathrm{PM}_{2.5}$ concentrations in other megacities, viz. Chennai ( 39\%), Bengaluru $(\sim 47 \%)$ and Kolkata ( 27\%) during March-April 2020 over 2019 has been reported ${ }^{36}$. Furthermore, studies over 22 cities across India revealed a maximum reduction in $\mathrm{PM}_{2.5}$ compared to other criteria pollutants during lockdown 2020 than previous three years.

During the entire lockdown phase (25 March 2020-31 May 2020), 42.35\% and 45\% reduction in $\mathrm{PM}_{10}$ and $\mathrm{PM}_{2.5}$ respectively, has been observed with an absolute reduction of $22.73 \mu \mathrm{g} \mathrm{m}^{-3}$ in $\mathrm{PM}_{10}$ and $15.3 \mu \mathrm{g} \mathrm{m}^{-3}$ in $\mathrm{PM}_{2.5}$ mass compared to PLD (1 March-24 March 2020). As a significant amount of $\mathrm{PM}_{2.5}$ has a regional background-origin, viz. traffic and industrial sources ${ }^{38}$, a complete lockdown along with frequent rain events reduced the $\mathrm{PM}_{2.5}$ concentrations during April to a greater extent. However, a slight relaxation of lockdown measures for movement of vehicles and operation of localized industries and business activities during May enhanced the $\mathrm{PM}_{2.5}$ concentrations by $\sim 42 \%$ compared to April.

\section{Conclusion}

Compared to the previous year, a reduction in anthropogenic activities along with meteorological influence brought a significant reduction $(33 \%)$ of $\mathrm{BC}$ mass concentration, $\mathrm{PM}_{10}(33 \%)$ and $\mathrm{PM}_{2.5}$ load (38\%) over Bhubaneswar during 2020 pre-monsoon period when a countrywide lockdown was imposed to deal with the current pandemic situation. Contribution of biomass burning to the overall $\mathrm{BC}$ mass was enhanced by $\sim 3.5$ times in comparison to previous years. It was interesting to note that a restriction of only the vehicular movement, even for a couple of weeks, resulted in a significant decline in $\mathrm{BC}$ mass and particulate matter concentration.

Disclaimer: The authors declare that they have no conflict of interest.
1. Helin, A. et al., Characteristics and source apportionment of black carbon in the Helsinki metropolitan area, Finland. Atmos. Environ., 2018, 190, 87-98.

2. Babu, S. S. and Moorthy, K. K., Anthropogenic impact on aerosol black carbon mass concentration at a tropical coastal station: a case study. Curr. Sci., 2001, 81(9), 1208-1214.

3. Reddy, M. S. and Venkataraman, C., Direct radiative forcing from anthropogenic carbonaceous aerosols over India. Curr. Sci., 1999, 76, 1005-1011.

4. Tiwari, V. S., Srivastava, A. K., Bisht, D. S., Parmita, P., Srivastava, M. J. and Attri, S. D., Diurnal and seasonal variations of black carbon and $\mathrm{PM}_{2.5}$ over New Delhi, India: Influence of meteorology. Atmos. Res., 2013, 125-126, 50-62.

5. Watson, J. G., Visibility: science and regulation. J. Air Waste Manage. Assoc., 2002, 52, 628-713.

6. Penner, J. E., Eddleman, H. and Novakov, T., Towards the development of a global inventory for black carbon emissions. Atmos. Environ., 1993, 27, 1277-1295.

7. Jacobson, M., Strong radiative heating due to the mixing state of B.C. in atmospheric aerosols. Nature, 2001, 409, 695-697.

8. Zhao, S., Yu, Ye., Yin, D., He, J., Liu, Na., Qu, J. and Xiao, J., Annual and diurnal variations of gaseous and particulate pollutants in 31 provincial capital cities based on in situ air quality monitoring data from China National Environmental Monitoring Center. Environ. Int., 2016, 86, 92-106.

9. Pillai, P. S., Babu, S. S. and Krishna Moorthy, K., A study of PM, $\mathrm{PM}_{10}$ and $\mathrm{PM}_{2.5}$ concentration at a tropical coastal station. Atmos. Res., 2002, 61(2), 149-167.

10. Satheesh, S. K., Atmospheric chemistry and climate. Curr. Sci., 2012, 102(3), 426-439.

11. Al-Hemoud, A., Al-Dousari, A., Al-Shatti, A., Al-Khayat, A., Behbehani, W. and Malak, M., Health impact assessment associated with exposure to $\mathrm{PM}_{10}$ and dust storms in Kuwait. Atmosphere, 2018, 9(1), 6 .

12. Seinfeld, J. H., Pandis, S. N. and Noone, K., Atmospheric chemistry and physics: from air pollution to climate change. Phys. Today, 1998, 51(10), 88.

13. Mahapatra, P. S., Sinha, P. R., Boopathy, R., Das, T., Mohanty, S. and Sahu, Seasonal progression of atmospheric particulate matter over an urban coastal region in peninsular India: Role of local meteorology and long-range transport. Atmos. Res., 2018, 199, $145-158$.

14. Panda, S. et al., A study on variation of atmospheric pollutants over Bhubaneswar during imposition of nationwide lockdown in India for the COVID-19 pandemic. Air Qual. Atmos. Health, 2020 , 14(1), 97-108.

15. Mallik, C., Mahapatra, P. S., Kumar, P., Panda, S., Boopathy, R., Das, T. and Lal, S., Influence of regional emissions on $\mathrm{SO}_{2}$ concentrations over Bhubaneswar, a capital city in eastern India downwind of the Indian $\mathrm{SO}_{2}$ hotspots. Atmos. Environ., 2019, 209, 220-232.

16. Mahapatra, P. S. et al., Seasonal trends, meteorological impacts, and associated health risks with atmospheric concentrations of gaseous pollutants at an Indian coastal city. Environ. Sci. Pollut. Res., 2014, 21, 11418-11432.

17. Sandradewi, J., Prévôt, A. S. H., Weingartner, E., Schmidhauser, R., Gysel, M. and Baltensperger, U., A study of wood burning and traffic aerosols in an Alpine valley using a multi-wavelength Aethalometer. Atmos. Environ., 2008, 42(1), 101-112.

18. Sandradewi, J. et al., Using aerosol light absorption measurements for the quantitative determination of wood burning and traffic emission contributions to particulate matter. Environ. Sci. Technol., 2008, 42(9), 3316-3323.

19. Titos, G. et al., Spatial and temporal variability of carbonaceous aerosols: assessing the impact of biomass burning in the urban environment. Sci. Total Environ., 2017, 578, 613-625. 
20. Mahapatra, P. S. et al., Urban air-quality assessment and source apportionment studies for Bhubaneshwar, Odisha. Theor. Appl. Climatol., 2013, 112, 243-251.

21. Sousan, S., Koehler, K., Laura Hallett and Peters, T. M., Evaluation of the alphasense optical particle counter (OPC-N2) and the grimm portable aerosol spectrometer (PAS-1.108). Aerosol Sci. Technol., 2016, 50(12), 1352-1365.

22. Cheng, Y.-H., Comparison of the TSI Model 8520 and Grimm Series 1.108 Portable Aerosol instruments used to monitor particulate matter in an iron foundry. J. Occup. Environ. Hyg., 2008 , 5(3), 157-168.

23. Burkart, J., Steiner, G., Reischl, G., Moshammer, H., Neuberger, M. and Hitzenberger, R., Characterizing the performance of two optical particle counters (Grimm OPC1.108 and OPC1.109) under urban aerosol conditions. J. Aerosol Sci., 2010, 41(10), S953S962.

24. Meng, C., Tianhai, Cheng., Xingfa, Gu., Shuaiyi, Shi., Wannan, Wang., Yu, Wu. and Fangwen, Bao, Contribution of meteorological factors to particulate pollution during winters in Beijing. Sci. Total Environ., 2019, 656, 977-985.

25. Pani, S. K., Neng-Huei, Lin. and Saginela, R., Association of COVID-19 pandemic with meteorological parameters over Singapore. Sci. Total Environ., 2020, 740.

26. Draxler, R. R. and Hess, G. D., An overview of the HYSPLIT_4 modeling system of trajectories, dispersion, and deposition. Aust. Meteor. Mag., 1998, 47, 295-308.

27. Draxler, R. R., HYSPLIT4 user's guide. NOAA Tech. Memo. ERL ARL-230, NOAA Air Resources Laboratory, Silver Spring, MD, 1999.

28. Giglio, L., Descloitres, J., Justice, C. O. and Kaufman, Y., An enhanced contextual fire detection algorithm for MODIS. Remote Sensing Environ., 2003, 87, 273-282.

29. Giglio, L., Schroeder, W. and Justice, C. O., The collection 6 MODIS active fire detection algorithm and fire products. Remote Sensing Environ., 2016, 78, 31-41.
30. Mahapatra, P. S. et al., Variation in black carbon mass concentration over an urban site in the eastern coastal plains of the Indian sub-continent. Theor. Appl. Climatol., 2014, 117, 133-147.

31. Reddy, B. S. K. et al., Potential source regions contributing to seasonal variations of black carbon aerosols over Anantapur in Southeast India. Aerosol Air Qual. Res., 2012, 12, 344-358.

32. Cape, J. N., Coyle, M. and Dumitrean, P., The atmospheric lifetime of black carbon. Atmos. Environ., 2012, 59, 256-263.

33. Wagner, S., Jaffe, R. and Stubbins, A., Dissolved black carbon in aquatic ecosystems. Limnol. Oceanogr., 2018, 3, 168-185.

34. Buseck, P. R., Adachi, K., Gelencsér, A., Tompa, É. and Pósfai, M., Are black carbon and soot the same? Atmos. Chem. Phys. Discuss., 2012, 12(9), 24821-24846.

35. Venkataraman, C., Habib, G., Eiguren-Fernandez, A., Miguel, A. H. and Friedlander, S. K., Residential biofuels in South Asia: carbonaceous aerosol emissions and climate impacts. Science, 2005, 307(5714), 1456.

36. Sharma, S. et al., Effect of restricted emissions during COVID-19 on air quality in India. Sci. Total Environ., 2020, 728, 138878.

37. Jain, S. and Sharma, T., Social and travel lockdown impact considering coronavirus disease (COVID-19) on air quality in megacities of India: present benefits, future challenges and way forward. Aerosol Air Qual. Res., 2020, 1222-1236.

38. Guttikunda, S. K., Nishadh, K. A. and Jawahar, P., Air pollution knowledge assessments (APnA) for 20 Indian cities. Urban Climate, 2019, 27, 124-141.

ACKNOWLEDGEMENTS. We thank the Director, CSIR-IMMT and Head of E\&S Department, CSIR-IMMT, Bhubaneswar for support. B.R. and T.D. thank ISRO-GBP (ATCTM \& ARFI) for the financial support. J.N. thanks DST for financial support.

doi: $10.18520 / \mathrm{cs} / \mathrm{v} 120 / \mathrm{i} 2 / 313-321$ 